\section{Aflibercept as primary treatment for myopic choroidal neovascularisation: a retrospective study}

C Bruè ${ }^{1,2}$, A Pazzaglia ${ }^{3}$, C Mariotti ${ }^{1}$, M Reibaldi $^{4}$ and A Giovannini ${ }^{1}$

\begin{abstract}
Aim The aim of this study is to evaluate long-term efficacy of intravitreal injections of aflibercept as primary treatment for subfoveal/juxtafoveal myopic choroidal neovascularisation (CNV).

Methods Thirty-eight treatment-naive eyes of thirty-eight patients with subfoveal/ juxtafoveal myopic $\mathrm{CNV}$ received initial intravitreal aflibercept injections and were followed for at least $\mathbf{1 8}$ months. Aflibercept was applied again for persistent or recurrent $\mathrm{CNV}$, as required. Statistical analysis was carried out using SPSS.

Results Mean patient age was 45.8 years, and mean eye refractive error was $-7.79 \mathrm{D}$. For the total patient group ( $n=38$ eyes), mean $\log$ MAR best-corrected visual acuity (BCVA) significantly improved from 0.69 at baseline to 0.15 at 18 months $(P<0.01)$. Over half of the treated eyes obtained resolution with one aflibercept injection. Patients were also grouped according to age, as $<50$ years ( $n=20$ eyes) and $\geq 50$ years ( $n=18$ eyes). Mean BCVA improvement was significantly greater in eyes of the younger myopic CNV group, compared with those of $\geq 50$ years (0.21 vs $0.35 ; P<0.05)$. The mean number of aflibercept injections was $\mathbf{1 . 8}$ for the $<\mathbf{5 0}$ years myopic CNV group, and 3.6 for the $\geq 50$ years myopic $\mathrm{CNV}$ group $(P<\mathbf{0 . 0 0 1})$. Correlation between spherical equivalent refraction and final visual acuity reached statistical significance only for the $<50$ years myopic CNV group $(P<0.001 ;$ Levene's correlation).

Conclusions Intravitreal aflibercept provides long-term visual acuity improvement in myopic CNV. The $<50$ years old myopic CNV group had significantly fewer injections, with greater visual acuity improvement. Intravitreal aflibercept in myopic CNV does not require the three-injection loading phase
\end{abstract}

used for aflibercept treatment of neovascular age-related macular degeneration.

Eye (2016) 30, 139-145; doi:10.1038/eye.2015.199; published online 30 October 2015

\section{Introduction}

Pathological myopia is one of the leading causes of visual impairment worldwide, and choroidal neovascularisation (CNV) is one of the most sightthreatening complications in patients affected with pathological myopia. ${ }^{1}$ The estimated risk for development of CNV from pathological myopia has been estimated as $4-10 \%$, and the natural course of subfoveal CNV is generally poor. ${ }^{2}$ Indeed, a large proportion of patients with myopia will have progression of myopic maculopathy, and a consequent visual loss.

Photodynamic therapy (PDT) has been one of the treatments of choice for myopic CNV over the past decade, and several studies have demonstrated that compared with placebo, PDT can reduce the risk of visual loss. ${ }^{3,4}$ However, patients treated with PDT do not gain better mean visual acuity, and PDT does not prevent visual loss for longer than 2 years. ${ }^{5}$

In recent years, the short-term efficacy of intravitreal anti-vascular endothelial growth factor (VEGF) agents has been shown for the arrest of myopic CNV, which have included bevacizumab $^{6}$ and ranibizumab. ${ }^{7}$ The majority of the studies with these agents have reported significant mean visual acuity improvements at 12 months. Other more recent studies have shown longer-term visual results for treatment of myopic CNV for up to 2 years after intravitreal injections of bevacizumab. 8,9 However, some discrepancies have been detected for such longer-term visual outcomes; indeed, it has been demonstrated that the initial visual gain with bevacizumab is not significantly maintained at 2 years. ${ }^{9,10}$ This appears to be

\author{
${ }^{1}$ Ophthalmology, \\ Department of \\ Neuroscience, Polytechnic \\ University of Marche, \\ Ancona, Italy \\ ${ }^{2}$ Ophthalmology, Macerata \\ Hospital, Macerata, Italy \\ ${ }^{3}$ Ophthalmology, \\ Sant'Orsola Hospital, \\ Malpighi, Italy \\ ${ }^{4}$ Ophthalmology, \\ G. Rodolico Vittorio \\ Emanuele Hospital, \\ Catania, Italy \\ Correspondence: \\ C Bruè, Ophthalmology, \\ Department of \\ Neuroscience, Polytechnic \\ University of Ancona, Via \\ Brecce Bianca, Ancona \\ 60020, Italy \\ Tel: +39071 5961; \\ Fax: +390715964392. \\ E-mail: claudia.brue@ \\ gmail.com
}

Received: 27 February 2015 Accepted in revised form: 31 July 2015 Published online: 30 October 2015 
because patients with myopic CNV who were treated with this anti-VEGF agent had undergone prior treatments, with some of these treatments being for nonsubfoveal CNV.

The use of aflibercept (Eylea; Regeneron, Tarrytown, NY, USA; Bayer, Basel, Switzerland) has been introduced more recently, which is a recombinant fusion protein that binds all isoforms of VEGF, and also placental growth factor. ${ }^{11}$ Aflibercept recently obtained US Food and Drug Administration approval for the treatment of neovascular age-related macular degeneration (AMD). ${ }^{12}$ With treatment of aflibercept every 2 months following 3-monthly loading doses, it was shown to be non-inferior to monthly injections of ranibizumab, in terms of patients who maintained or improved their vision at 12 months. These aflibercept benefits were also maintained to 2 years. $^{12}$

However, there remain discrepancies in the literature about the efficacy of ranibizumab and bevacizumab for maintenance of good visual acuity over 2 years of treatment of patients with myopic CNV. Thus, considering also the relative lack of data for aflibercept treatment for these patients, we investigated the longterm visual outcome of patients with myopic CNV treated with aflibercept.

\section{Materials and methods}

This was a retrospective study of consecutive patients with subfoveal/juxtafoveal CNV secondary to pathological myopia who received intravitreal aflibercept injections. The treatments were carried out in the Department of Ophthalmology, Polytechnic University of Marche, Ancona (Italy), and informed consent was obtained from all of the patients before treatment.

The inclusion criteria included: treatment-naive patients with follow-up of $\geq 18$ months; myopia with a spherical equivalent refractive error of $\geq-5 \mathrm{D}$; active $\mathrm{CNV}$, as documented by fluorescein angiography and SD-OCT (spectral-domain optical coherence tomography); subfoveal-juxtafoveal CNV; and bestcorrected visual acuity (BCVA) 20/800 or better. The exclusion criteria included: prior treatments for $\mathrm{CNV}$, including PDT and thermal laser photocoagulation; history of intraocular surgery; extrafoveal CNV; CNV from ocular pathology other than pathological myopia, such as AMD, choroiditis, angioid streaks, and trauma; and hereditary disease in the studied and fellow eye.

At baseline and at all subsequent visits, complete ophthalmic examinations were carried out, which included Snellen BCVA (converted to the logarithm of the minimum angle of resolution; $\log \mathrm{MAR}$ ), slit-lamp biomicroscopy, tonometry, fundus examination, and fluorescein angiography. Fundus photography and
SD-OCT (Topcon America, Paramus, NJ, USA; Heidelberg Engineering Inc., Dossenheim, Germany) were performed at baseline, and at 1 week and 1, 2, 3, 6, 12 , and 18 months after aflibercept injection.

Intravitreal injections of aflibercept $2 \mathrm{mg}$ were carried out using a 30-gauge needle, at $4 \mathrm{~mm}$ from the limbus and under aseptic conditions. Retreatment with aflibercept was performed based on the presence of active leakage on fluorescein angiography, persistent subretinal fluid on SD-OCT, or new haemorrhage, with minimum 3-monthly retreatments maintained.

Statistical analysis was carried out using SPSS (Version 17.0; SPSS Inc., Chicago, IL, USA). The patients were analysed according to both the total patient group and the age groups of $<50$ years $v s \geq 50$ years. Paired $t$-tests were performed to evaluate the effects of the post-treatment visual outcome $v$ s baseline (pre-treatment). The differences in the visual outcomes between the two age groups were compared using two-sample $t$-tests. Linear regression was performed to determine the effects on visual outcome of baseline BCVA, age, spherical equivalent, and number of injections. A P-value of $<0.05$ was considered as statistically significant.

We certify that all applicable institutional and governmental regulations concerning the ethical use of human volunteers were followed during this study.

\section{Results}

In all, 38 eyes from 38 patients ( 24 women and 14 men) were included in the study, and the baseline and clinical characteristics of these patients are given in Table 1. For the total patient group, the baseline mean age ( \pm standard deviation [SD]) was 45.8 years ( \pm 20.5 years; range, $22-79$ years). The CNV was seen for 30 right eyes (79\%) and 8 left eyes $(21 \%)$. The baseline mean spherical equivalent refractive index was $-7.79 \mathrm{D}( \pm 3.75 \mathrm{SD}$; range, -5.00 to -12.50). The mean follow-up time was $21 \pm 1.9$ months.

For the total patient group, the mean BCVA $( \pm S D)$ improved significantly, from $0.69 \pm 0.30 \log$ MAR at baseline to $0.15 \pm 0.09 \log$ MAR at 18 months $(P<0.001)$ (Figure 1). The mean central foveal thickness decreased significantly from $276 \mu \mathrm{m}$ at baseline to $215 \mu \mathrm{m}$ at 18 months $(P<0.001)$ (Table 2$)$. Paired $t$-tests also demonstrated significant improvement in BCVA compared with baseline at $1,3,6,12$, and 18 months $(P<0.001)$. The greatest improvements were seen within the first 3 months of the initial aflibercept injection, and the BCVA remained stable thereafter. Overall, 55\% $(21 / 38)$ of the patients achieved resolution of their myopic CNV with a single aflibercept injection. Thus, 19 of the 38 patients $(50 \%)$ received $>1$ aflibercept injection, with a total of 79 aflibercept injections given to the 18 months of follow-up (ie, mean, 2.1 aflibercept injections/patient). 
In detail, over the 18 months of follow-up, 50\% of patients received one injection, $18.4 \%$ received two injections, $10.5 \%$ received three injections, $15.8 \%$ received four injections, and $5.3 \%$ received five injections.

The further analysis provided 20 eyes for patient s aged $<50$ years, and 18 eyes for those aged $\geq 50$ years. The mean number of aflibercept injections was 1.5 for the $<50$ years myopic CNV group, and 2.7 for the $\geq 50$ years myopic CNV group $(P<0.001)$. Indeed, $60 \%(12 / 20)$ of the treated eyes of the patients $<50$ years old obtained resolution with just one injection, which was significantly greater than that seen for the treated eyes of the patients $\geq 50$ years old (60 vs $49 \%$, respectively; $P<0.05)$.

The mean BCVA improvement was greater in the younger group ( $<50$ years) compared with the $\geq 50$ years (0.64 vs 0.38 , respectively; $P<0.05$ ) (Figure 2 ). In the 18 months of follow-up, the $<50$ year patients showed significantly better BCVA improvement than those of $\geq 50$ years $(0.21 \pm 0.12$ vs $0.35 \pm 0.12$, respectively; $P<0.05)$.

In the comparison of spherical equivalent refraction between the patients of $<50 v s \geq 50$ years, at baseline the young patients were more myopic than the old patients (-9.9 vs -5.5), although this difference did not reach statistical significance. With stratification by age, the correlation between the spherical equivalent refraction and the final visual acuity showed significance only for the patients of $<50$ years ( $P<0.001$; Levene's correlation) (Figure 3), as the correlation lost significance for the patients of $\geq 50$ years. This suggests that spherical equivalent refraction is also predictive of the final visual acuity, and that higher myopia relates to worse visual acuity in young patients.

In the linear regression analysis of the total patient group, after adjusting for age, spherical equivalent refraction, and number of injections, baseline BCVA was the most predictive factor for the visual outcome $(P<0.001)$. Baseline spherical equivalent refraction did not correlate with initial and final BCVA $(P>0.05$; Levene's correlation). No relevant ocular or systemic complications were detected.

\section{Discussion}

Several treatments have been proposed for myopic CNV, such as laser photocoagulation, surgical removal of $\mathrm{CNV}$, macular translocation, and PDT without and with intravitreal triamcinolone acetonide. However, the most appropriate treatment remains to be established. Laser photocoagulation should not be considered in juxtafoveal cases, as the long-term expansion of the laser scar can cause decreased visual acuity; this is however not a concern for extrafoveal cases. ${ }^{13}$

PDT with benzoporphyrin, a derivative verteporfin, is a treatment option for subfoveal CNV in pathological myopia. Treatment with PDT has been described to provide more stable visual acuity compared with placebo. ${ }^{4}$ However, more recently, intravitreal injections of anti-VEGF agents have been proposed as the main therapy for the treatment of myopic CNV. ${ }^{14,15}$ Indeed, previous reports have shown that these agents can provide good outcomes in the treatment of myopic CNV. However, most of these studies included patients who

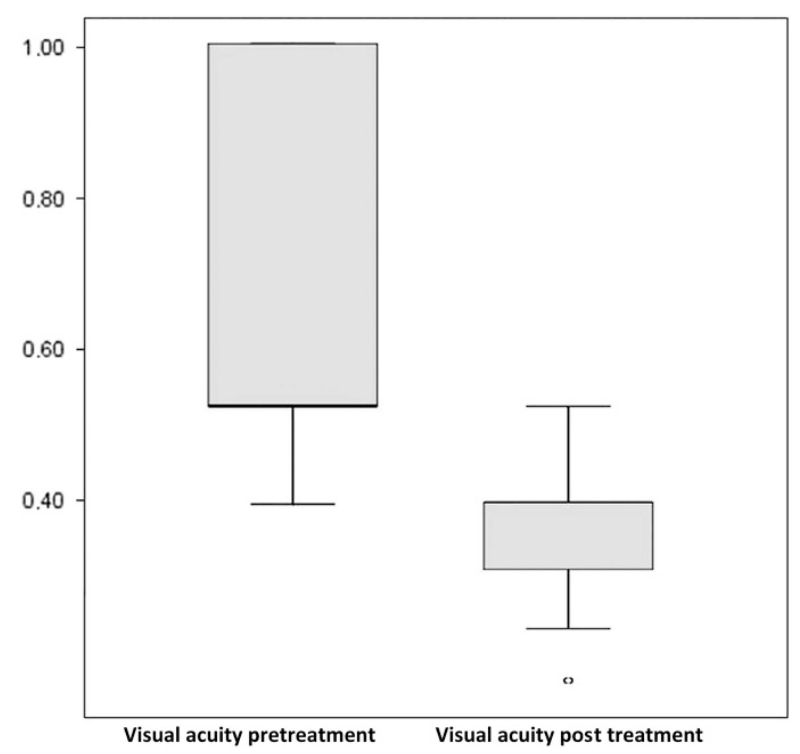

Figure 1 Initial and final BCVA for the total patient group.

Table 1 Baseline demographic and clinical data for the full patient group, and for the $<50$ and $\geq 50$ years patient groups

\begin{tabular}{lcccc}
\hline Parameter & $\begin{array}{c}\text { Total patient } \\
\text { group }(38 \text { eyes })\end{array}$ & $\begin{array}{c}\text { Patients }<50 \\
\text { years }(20 \text { eyes })\end{array}$ & $\begin{array}{c}\text { Patients } \geq 50 \\
\text { years }(18 \text { eyes })\end{array}$ & $\begin{array}{c}\text { P-value } \\
(<50 \text { vs } \geq 50)\end{array}$ \\
\hline Age (years) & 45.76 & $27.25( \pm 6.28)$ & $66.33( \pm 4.63)$ & $<0.05$ \\
Gender (male: $n[\%])$ & $14[36.8]$ & $6[30.0]$ & $8[44.44]$ & $\mathrm{NS}$ \\
Eye side (right: $n[\%])$ & $30[79.0]$ & $20[100]$ & $10[55.55]$ & $\mathrm{NS}$ \\
Spherical equivalent $(\mathrm{D})$ & $-7.79( \pm 3.75)$ & $-9.93( \pm 0.85)$ & $-5.58( \pm 2.19)$ & $\mathrm{NS}$ \\
BCVA (logMAR) & $0.69( \pm 0.30)$ & $0.86( \pm 0.22)$ & $0.73( \pm 0.25)$ & 267 \\
Mean central foveal thickness $(\mu \mathrm{m})$ & 276 & 285 & & \\
\hline
\end{tabular}

Abbreviation: NS, non-significant. Data are means $( \pm S D)$ or as indicated. 
Table 2 Clinical data after 18 months of follow-up for the full patient group, and for the $<50$ and $\geq 50$ years patient groups

\begin{tabular}{lccccc}
\hline \multirow{2}{*}{ Parameter } & \multicolumn{2}{c}{ Total patient group } & $\begin{array}{c}\text { Patients }<50 \\
\text { years (20 eyes) }\end{array}$ & $\begin{array}{c}\text { Patients } \geq 50 \\
\text { years }(18 \text { eyes })\end{array}$ & $\begin{array}{c}\text { P-value } \\
(<50 \text { years vs } \geq 50 \text { years })\end{array}$ \\
\cline { 2 - 5 } & Value (38 eyes) & $\begin{array}{c}\text { P-value } \\
\text { (baseline vs } 18 \text { months) }\end{array}$ & \\
\hline BCVA (logMAR) & $0.15 \pm 0.09$ & $<0.001$ & $0.21( \pm 0.12)$ & $0.34( \pm 0.12)$ & $<0.001$ \\
Mean central foveal thickness $(\mu \mathrm{m})$ & 215 & $<0.001$ & $210( \pm 13.00)$ & $211( \pm 12.78)$ & $>0.05$ \\
\hline
\end{tabular}

Data are means $( \pm S D)$ or as indicated.

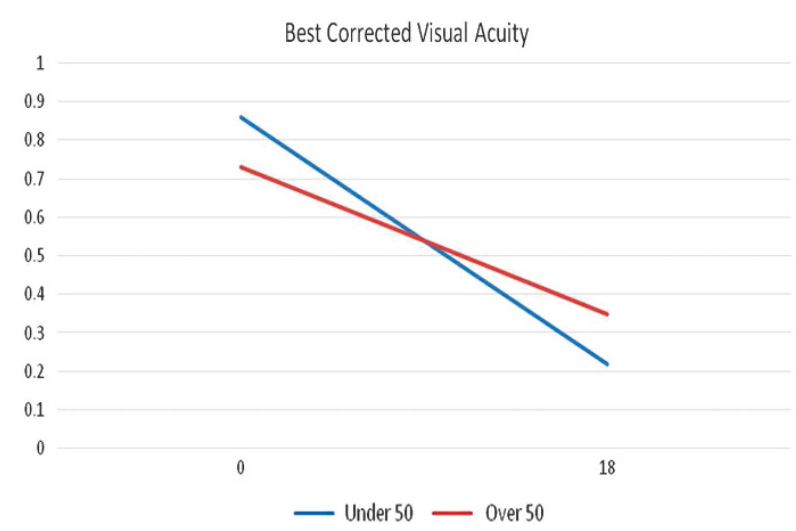

Figure 2 Comparison of the mean BCVA improvement in the young group $(<50$ years $)$ compared with the $\geq 50$-yearold group.

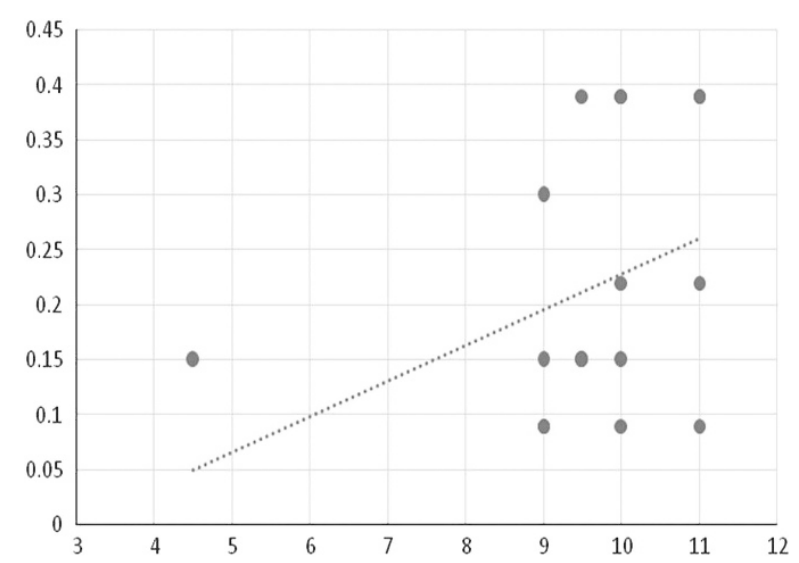

Figure 3 Correlation between the spherical equivalent refraction and the final visual acuity for the patients of $<50$ years.

had been previously treated with PDT, and also included older subjects. ${ }^{16-18}$

Previous studies by Gharbiya et $a l^{8}$ and Nakanishi et $a l^{16}$ showed that patients with myopic $\mathrm{CNV}$ can gain significant visual improvement to 2 years following monthly intravitreal injections of bevacizumab. However, Ruiz-Moreno et $a l^{9}$ and Ikuno et al ${ }^{10}$ demonstrated that the initial visual improvements in these patients were no longer significant after 2 years of monthly intravitreal bevacizumab therapy. This lack of significant visual improvement in these two latter studies might be explained by the relatively small sample sizes for the patients studied by Ruiz-Moreno et $a l^{9}$ and the inclusion of only patients $>50$ years old by Ikuno et al. ${ }^{10}$ In the present study, we detected better visual acuity in patients aged $<50$ years in the first 18 months of follow-up, which is in agreement with the clinical findings of Yoshida et al, ${ }^{19}$ who also showed similar clinical progress based on the patient's age.

This can be explained by several factors, such as decreased integrity and function of the myopic retinal pigment epithelium in older patients, which might reduce the inhibition of angiogenesis, with the consequent larger and more active $\mathrm{CNV}$, as well as a delay in the regression of CNV in these older patients. ${ }^{20}$ Indeed, myopic CNV in older patients can present clinical and pathophysiological features of both AMD and high myopia, with poor natural outcome. Older patients tend to develop chorioretinal atrophy degeneration, which is a condition that negatively influences the final visual acuity in these patients. In the present study, the patients were balanced for age and sex, and these factors did not influence the significantly better final visual acuity at 18 months, compared with baseline.

Our findings show that the patients with myopic subfoveal-juxtafoveal CNV had a mean improvement of five lines at 18 months from baseline, following the intravitreal aflibercept injections. Of note, the treatment of subfoveal myopic CNV with PDT has also been reported to show no significant improvements at 2 years, ${ }^{5}$ with several studies demonstrating such inferior visual outcomes correlated to PDT. ${ }^{21,22}$ An explanation here might relate to the enlargement of chorioretinal atrophy around the CNV following PDT, as eyes affected by pathological myopia do not show any increased scarring after treatment: the reduced number of injections might explain the absence of chorioretinal atrophy associated with $\mathrm{CNV}$. On the basis of a prospective randomised clinical trial, the RADIANCE study, that demonstrated a superiority of intravitreal ranibizumab over PDT, ranibizumab has recently received approval in the European Union as the first effective anti-VEGF treatment for myopic CNV. The study proved that $40 \%$ of patients 
treated with ranibizumab, as opposed to $15 \%$ of PDT, gained 15 or more letters of visual acuity at 3 months. ${ }^{23}$ The mean visual acuity gain was $\sim 14$ Early Treatment Diabetic Retinopathy Study letters at 1 year at a mean of 3.5 ranibizumab injections. In detail, $50 \%$ of the patients required 1-2 injections, $36 \%$ required 3-5 injections, and $14 \%$ required 6-12 injections over the 12-month study. In our series of patients, $68.4 \%$ of them received $1-2$ injections of aflibercept, $31.6 \%$ required 3-5 injections, and $0 \%$ required $6-12$ injections over the 18-month follow-up. Indeed, CNV myopic eyes treated with aflibercept required a significant lower number of injections considering the longer follow-up of 18 months.

A potential risk associated with the treatment of myopic CNV with anti-VEGFs is the formation of marginal crack lines after treatment-related contraction of the myopic CNV, which is considered as early damage of the retinal pigment epithelium that might lead to expanding macular chorioretinal atrophy. This factor, in conjunction with treatment-related cumulative damage to the photoreceptors and the underlying retinal pigment epithelium, might compromise the long-term results, as underlined by the relatively few aflibercept injections needed in the present study. Several studies ${ }^{24-27}$ and an open-label, non-comparative phase II trial known as REPAIR (Ranibizumab for the trEatmentof CNV secondary to pathological myopia; an Individualised Regimen ${ }^{28,29}$ have shown beneficial results of intravitreal ranibizumab for myopic CNV. Twelve-month data from the phase II study indicated that ranibizumab was associated with significant improvements of BCVA score and central macular thickness. Furthermore, fewer eyes had subretinal fluid, intraretinal cysts, or oedema at 12 months than at baseline ( 7.7 vs $67.7 \%, 13.8$ vs $52.3 \%$, 7.7 vs $87.7 \%$, respectively). Nevertheless, further long-term data for ranibizumab are missing, including data relating to any potential for geographic atrophy, the risk of which was increased with ranibizumab in a recent AMD study. ${ }^{30}$ To date, there are no data about the long-term effect of ranibizumab on myopic CNV. A prospective, observational study (LUMINOUS) is ongoing for the evaluation of long-term safety and efficacy of ranibizumab in routine clinical practice. ${ }^{31}$

For the reduced number of aflibercept injections that were required, this can be explained by the decreased aggressiveness of myopic $\mathrm{CNV}$ compared with $\mathrm{AMD}$ and by the characteristics of aflibercept compared with the other anti-VEGF agents. Indeed, aflibercept binds placental growth factor in addition to both the VEGF-A and VEGF-B isoforms. Placental growth factor is present in human $\mathrm{CNV}$, and animal studies have demonstrated that it can promote the development of experimental CNV. Furthermore, aflibercept has a high affinity for VEGF (Kd, $0.5 \mathrm{pM})$, which is considerably greater than that of ranibizumab and bevacizumab for VEGF, and also of VEGF for its receptors. ${ }^{23}$ This provides effective blocking of VEGF with longer duration of action, which thus also promotes extended dosing intervals. Indeed, the 1-year results from the VIEW 1 and VIEW 2 studies showed that in the treatment of CNV due to AMD, aflibercept was noninferior under similar dosing regimens to ranibizumab. ${ }^{24-28}$ Here, aflibercept maintained the visual gains obtained in the first year of the study with significantly fewer injections compared with ranibizumab.

The 1-year data from the CLEAR-IT 2 study also demonstrated good visual and anatomical outcome with aflibercept. After one injection per month for 3 months, only one or two more injections were needed per eye (with the treatment on an as-required basis, as in the present study), with a mean time for reinjection of 129 days (ie, every $\sim 4.5$ months). ${ }^{32}$ These outcomes were similar to the ANCHOR, ${ }^{33}$ MARINA, ${ }^{34}$ and PRONTO $^{35}$ ranibizumab trials for the initial monthly regime of three injections, and in particular, these all indicated the need for less frequent dosing of aflibercept.

This has been confirmed also in the present study for the treatment of myopic CNV. In particular, we have shown the need for significantly fewer aflibercept injections for the $<50$ years myopic $\mathrm{CNV}$ group compared with the $\geq 50$ years myopic $\mathrm{CNV}$, and over half of the total treated eyes obtained resolution with just one aflibercept injection. This suggests that a three-injection loading phase is not necessary for young patients affected by myopic $\mathrm{CNV}$ who are treated with aflibercept. The good function of retinal pigment epithelium cells in young patients will also allow greater inhibition of $\mathrm{CNV}$ growth compared with the older subjects.

Aflibercept is a promising option for patients with naive myopic CNV due to its high binding affinity and extended duration of action. This latter quality is particularly relevant, because pathological myopia is a chronic disease and it mainly affects patients of working age. Thus for these patients, aflibercept can be considered as a valid alternative to other anti-VEGF agents, also with apparently fewer injections needed for the treatment. Indeed, as in previous trials in patients with $\mathrm{AMD}^{36,37}$ and although not examined directly here for these patients with naive myopic $\mathrm{CNV}$, the collected data indicate similar visual acuity obtained for aflibercept when compared with ranibizumab and bevacizumab, but with a longer duration of action for aflibercept, and thus fewer injections needed. Furthermore, considering the reduced number of aflibercept injections on a pro re nata basis observed in our study, this will also reduce the burden on the health services and reduce the discomfort for the patient.

Therefore, this combination of the efficacy, duration of action, economics, patient benefit, and safety profiles of 
intravitreal aflibercept now indicate the need for a shift in the treatment choice for patients with naive myopic $\mathrm{CNV}$.

\section{Summary}

\section{What was known before}

- Patients with naive myopic choroidal neovascularisation $(\mathrm{CNV})$ treated with photodynamic therapy do not gain better mean visual acuity, and it does not prevent visual loss for $>2$ years.

- More recent treatments have including intravitreal antiVEGF agents bevacizumab and ranibizumab. However, discrepancies have also been seen for longer-term visual outcomes of anti-VEGF injections, with initial visual gain not significantly maintained at 2 years.

- Aflibercept binds all isoforms of VEGF, and placental growth factor. It is a promising option for patients with naive myopic $\mathrm{CNV}$, due to its high binding affinity and extended duration of action.

\section{What this study adds}

- At 18 months follow-up, over half of the total treated eyes obtained resolution with just one aflibercept injection. Significantly fewer aflibercept injections were required for patients of $<50$ years old, compared with those of $\geq 50$ years old.

- Following aflibercept injections, correlation between spherical equivalent refraction and final visual acuity was significance for patients of $<50$ years old.

- Intravitreal aflibercept provides long-term visual acuity improvement in nave myopic CNV. Aflibercept can be considered as a valid alternative to other anti-VEGF agents for these patients, with improved benefits for those of $<50$ years old.

\section{Conflict of interest}

The authors declare no conflict of interest.

\section{References}

1 Wong TY, Foster PJ, Hee J, Ng TP, Tielsch JM, Chew SJ et al. Prevalence and risk factors for refractive errors in adult Chinese in Singapore. Invest Ophthalmol Vis Sci 2000; 41: 2486-2494.

2 Yoshida T, Kyoko Ohno-Matsui K, Ohtake Y, Takashima T, Futagami S, Baba T et al. Long-term visual prognosis of choroidal neovascularization in high myopia. A comparison between age groups. Ophthalmology 2002; 109: 712-719.

3 Lam DSC, Chan W-M, Liu DTL, Fan DSP, Lai WW, Chong KKL. Photodynamic therapy with verteporfin for subfoveal choroidal neovascularization of pathological myopia in Chinese eyes: a prospective series of 1 and 2 year follow up. Br J Ophthalmol 2004; 88: 1315-1319.

4 Blinder KJ, Blumenkranz MS, Bressler NM, Bressler SB, Donato G, Lewis $\mathrm{H}$ et al. Verteporfin therapy of subfoveal choroidal neovascularization in pathologic myopia: 2 year results of a randomized clinical trial - VIP report no 3. Ophthalmology 2003; 110: 667-673.
5 Chan WM, Ohji M, Lai TY, Liu DT, Tano Y, Lam DS. Choroidal neovascularization in pathological myopia: an update in management. Br J Ophthalmol 2005; 89: 1522-1528.

6 Yamamoto I, Rogers AH, Reichel E, Yates PA, Duker JS. Intravitreal bevacizumab (Avastin) as treatment for subfoveal choroidal neovascularization secondary to pathologic myopia. Br J Ophthalmol 2007; 91: 157-160.

7 Gharbiya M, Giustolisi R, Allievi F, Fantozzi N, Mazzeo L, Scavella V et al. Choroidal neovascularization in pathologic myopia: intravitreal ranibizumab versus bevacizumab: a randomized controlled trial. Am J Ophthalmol 2010; 149: 458-464.

8 Gharbiya M, Allievi F, Conflitti S, Esposito M, Scavella V, Moramarco et al. Intravitreal bevacizumab for treatment of myopic choroidal neovascularization: the second year of prospective study. Clin Ter 2010; 161: e87-e93.

9 Ruiz-Moreno JM, Montero JA. Intravitreal bevacizumab to treat myopic choroidal neovascularization: 2-year outcome. Graefes Arch Clin Exp Ophthalmol 2010; 248: 937-941.

10 Ikuno Y, Nagai Y, Matsuda S, Arisawa A, Sho K, Oshita T et al. Two years visual results for older Asian women treated with photodynamic therapy or bevacizumab for myopic choroidal neovascularization. Am J Ophthalmol 2010; 149: 140-146.

11 Sophie R, Akhar A, Sepah YJ, Ibrahim M, Bittencourt M, Do DV et al. Aflibercept: a potent vascular endothelial growth factor antagonist for neovascular age-related macular degeneration and other retinal vascular diseases. Biol Ther 2012; 2: 1-22.

12 Elshout M, van der Reis MI, Webers CA, Schouten JS. The cost-utility of aflibercept for the treatment of age-related macular degeneration compared to bevacizumab and ranibizumab and the influence of model parameters. Graefes Arch Clin Exp Ophthalmol 2014; 252: 1911-1920.

13 Jalkh AE, Weiter JJ, Trempe CL, Pruett RC, Schepens CL. Choroidal neovascularization in degenerative myopia: role of laser photocoagulation. Ophthalmic Surg 1987; 18: 721-725.

14 Lai TY, Chan WM, Liu DT, Lam DS. Intravitreal ranibizumab for the primary treatment of choroidal neovascularization secondary to pathologic myopia: 12-month results. Eye 2009; 23: 1275-1280.

15 Lai TY, Luk FO, Lee GK, Lam DS. Long-term outcome of intravitreal anti-vascular endothelial growth factor therapy with bevacizumab or ranibizumab as primary treatment for subfoveal myopic choroidal neovascularization. Eye 2012; 26: 1004-1011.

16 Nakanishi H, Tsujikawa A, Yodoi Y, Ojima Y, Otani A, Tamura $\mathrm{H}$ et al. Prognostic factors for visual outcomes 2 years after intravitreal bevacizumab for myopic choroidal neovascularization. Eye 2011; 25: 375-381.

17 Hayashi K, Shimada N, Moriyama M, Hayashi W, Tokoro T, Ohno-Matsui K. Two-year outcomes of intravitreal bevacizumab for choroidal neovascularization in Japanese patients with pathologic myopia. Retina 2012; 32: 687-695.

18 Yoon JU, Kim YM, Lee SJ, Byun YJ, Koh HJ. Prognostic factors for visual outcome after intravitreal anti-VEGF injection for naïve myopic choroidal neovascularization. Retina 2012; 32: 949-955.

19 Yoshida T, Ohno-Matsui K, Ohtake Y, Takashima T, Futagami S, Baba $\mathrm{T}$ et al. Long-term visual prognosis of choroidal neovascularization in high myopia: a comparison between age groups. Ophthalmology 2002; 109: 712-719.

20 Baba T, Kubota-Taniai M, Kitahashi M, Okada K, Mitamura Y, Yamamoto S. Two-year comparison of photodynamic therapy 
and intravitreal bevacizumab for treatment of myopic choroidal neovascularization. Br J Ophthalmol 2010; 94: 864-870.

21 Yoon JU, Byun YJ, Koh HJ. Intravitreal anti-VEGF versus photodynamic therapy with verteporfin for treatment of myopic choroidal neovascularization. Retina 2010; 30: 418-424.

22 Ohr M, Kaiser PK. Aflibercept in wet age-related macular degeneration: a perspective review. Ther Adv Chronic Dis 2012; 3: 153-161.

23 Wolf S, Balciuniene VI, Laganovska G, Menchini U, Ohno-Matsui K, Sharma T et al. RADIANCE: a randomized controlled study of a ranibizumab in patients with choroidal neovascularization secondary to pathologic myopia. Ophthalmology 2014; 121: 682-692.

24 Ladaique M, Dirani A, Ambresin A. Long-term follow-up of choroidal neovascularization in pathological myopia treated with intravitreal ranibizumab. Klin Monbl Augenheilkd 2015; 232: 542-547.

25 Pasyechnikova NV, Naumenko VO, Korol AR, Zadorozhnyy OS, Kustryn TB, Henrich PB. Intravitreal ranibizumab for the treatment of choroidal neovascularizations associated with pathologic myopia: a prospective study. Ophthalmologica 2015; 233: 2-7.

26 Claxton L, Malcolm B, Taylor M, Haig J, Leteneux C. Ranibizumab, verteporfin photodynamic therapy or observation for the treatment of myopic choroidal neovascularization: cost effectiveness in the UK. Drugs Aging 2014; 31: 837-848.

27 Deeks ED. Ranibizumab: a review of its use in myopic choroidal neovascularization. BioDrugs 2014; 28: 403-410.

28 Tufail A, Narendran N, Patel PJ, Sivaprasad S, Amoaku W, Browning AC et al. Ranibizumab in myopic choroidal neovascularization: the 12-month results from the REPAIR study. Ophthalmology 2013; 120: 1944-1945.

29 Tufail A, Patel PJ, Sivaprasad S, Amoaku W, Browning AC, Cole $\mathrm{M}$ et al. Ranibizumab for the treatment of choroidal neovascularisation secondary to pathological myopia: interim analysis of the REPAIR study. Eye 2013; 27: 709-715.

30 Grunwald JE, Daniel E, Huang J, Ying GS, Maguire MG, Toth CA et al. Risk of geographic atrophy in the comparison of age-related macular degeneration treatments trials. Ophthalmology 2014; 121: 150-161.
31 Novartis Pharmaceuticals. Observe the effectiveness and safety of ranibizumab in reallife setting (LUMINOUS) [ClinicalTrials.gov identifier NCT01318941]. US National Institutes of Health, http:www.clinicaltrials.gov.2013.

32 Yuzawa M, Fujita K, Wittrup-Jensen KU, Norenberg C, Zeitz $\mathrm{O}$, Adachi $\mathrm{K}$ et al. Improvement in vision-related function with intravitreal aflibercept: data from phase 3 studies in wet age-related macular degeneration. Ophthalmology 2015; 122: 571-578.

33 Heier JS, Boyer D, Nguyen QD, Marcus D, Roth DB, Yancopoulos G et al. The 1-year results of CLEAR-IT 2, a phase 2 study of vascular endothelial growth trap-eye dosed as-needed after 12-week fixed dosing. Ophthalmology 2011; 118: 1098-1106.

34 Brown DM, Kaiser PK, Michels M, Soubrane G, Heier JS, Kim RY et al. Ranibizumab versus verteporfin for neovascular age-related macular degeneration. $N$ Engl J Med 2006; 355: 1432-1444.

35 Rosenfeld PJ, Brown DM, Heier JS, Boyer DS, Kaiser PK, Chung CY et al. Ranibizumab for neovascular age-related macular degeneration. N Engl J Med 2006; 355: 1419-1431.

36 Wolf A, Reznicek L, Muhr J, Ulbig M, Kampik A, Haritoglou C. [Treatment of recurrent neovascular age-related macular degeneration with ranibizumab according to the PrONTO scheme]. Ophthalmologe 2013; 110: 740-745 [German].

37 Do DV, Schmidt-Erfurth U, Gonzalez VH, Gordon CM, Tolentino M, Berliner AJ et al. The DA VINCI study: phase 2 primary results of VEGF Trap-Eye in patients with diabetic macular edema. Ophthalmology 2011; 118: 1819-1826.

cc) (i) $(-)(-)$ This work is licensed under a Creative Commons Attribution-NonCommercial-NoDerivs 4.0 International License. The images or other third party material in this article are included in the article's Creative Commons license, unless indicated otherwise in the credit line; if the material is not included under the Creative Commons license, users will need to obtain permission from the license holder to reproduce the material. To view a copy of this license, visit http://creativecommons.org/licenses/by-nc$\mathrm{nd} / 4.0 /$ 